\title{
GAMBARAN PELAKSANAAN INISIASI MENYUSU DINI DI RUMAH SAKIT IBU DAN ANAK PERTIWI MAKASSAR TAHUN 2019
}

\author{
*)Saniasa Luba \\ *)Akademi Kebidanan Sandi Karsa Makassar \\ *)Program Studi D-III Kebidanan Sandi Karsa Makassar
}

\begin{abstract}
ABSTRAK
Telah dilakukan penelitian tentang Gambaran Pelaksanaan Inisiasi Menyusu Dini Di Rumah Sakit Ibu Dan Anak Pertiwi. Penelitian ini dilaksanakan pada bulan Maret 2019 dengan desain penelitian deskriptif dengan teknik pengambilan sampel total sampling yaitu seluruh ibu bersalin yang berjumlah 30 pada saat dilakukan penelitian. Instrumen pengumpulan data berupa lembar observasi yang terdiri dari 6 prosedur/tidakan dala penerapan inisiasi menyusu dini. Penelitian ini dilakukan di Rumah Sakit Ibu dan Anak Pertiwi Makassar dengan sampel sebesar 30 persalinan. Dari hasil penelitian diperoleh, sebanyak 27 persalinan (90\%) yang tidak melakukan IMD dengan tepat dan 3 persalinan (10\%) yang melakukan IMD dengan tepat. Berdasarkan hasil penelitian disimpulkan bahwa di RSKDIA Pertiwi Makassar belum sepenuhnya dilakukan Inisiasi Menyusu Dini. Rumah Sakit diharapkan perlkuk membuat protap untuk petugas kesehatan agar disetiap persalinan dilakukan IMD segera setelah lahir.
\end{abstract}

Kata kunci: Inisiasi, Menyusu dini, Rumah Sakit Ibu dan Anak.

\section{PENDAHULUAN}

\section{A. Latar Belakang}

Di Indonesia pelaksanaan IMD disosialisasikan pada saat Pekan ASI se-Dunia tahun 2007. Pada kesempatan tersebut ibu Presiden Republik Indonesia menghimbau agar para ibu memberi kesempatan pada bayinya untuk menyusu dalam satu jam pertama setelah melahirkan. Oleh karena itu, Ibu Negara juga menghimbau semua petugas kesehatan yang terlibat dalam persalinan, termasuk para dokter dan bidan untuk membantu ibu-ibu melaksanakan IMD segera setelah melahirkan (Kementrian Koordinator Bidang Kesejahteraan Rakyat, 2007). IMD menjadi begitu penting untuk dilakukan karena sejak tahun 2008 dalam Asuhan Persalinan Normal (APN), IMD tersebut merupakan langkah terakhir yang harus dilakukan oleh petugas kesehatan yang membantu persalinan (Depkes, 2008).

IMD akhir-akhir ini banyak digaungkan The United Nations Children's Fund (UNICEF). Pemerintah Indonesia telah mencanangkan IMD sebagai bagian dari upaya mengoptimalisasi pemberian ASI yang relatif dengan ASI eklusif. IMD merupakan bagian dari manajemen laktasi yang relatif baru dan harus disosialisasikan secara benar ke masyarakat (Siregar, 2004).

Inisiasi menyusu dini yang disingkat dengan IMD merupakan program yang sedang dianjurkan pemerintah. Menyusu dan bukan menyusui merupakan gambaran bahwa IMD bukan program ibu menyusui bayi tetapi bayi yang harus aktif menemukan sendiri puting susu ibu. Program ini dilakukan dengan cara langsung meletakkan bayi baru lahir di dada ibunya dan membiarkan bayi ini merayap untuk menemukan puting susu ibu. Untuk menyusui, inisiasi menyusu dini harus dilakukan langsung saat lahir, tanpa boleh ditunda dengan kegiatan menimbang atau mengukur bayi. Proses ini berlangsung harus skin to skin antara ibu dan bayi (JNPK-KR, 2008). Inisiasi Menyusu Dini sering disalah diartikan sebagai memaksa bayi di payudara ibu segera setelah lahir. Bagaimanapun, jika dibiarkan kontak kulit ke kulit ibunya, bayi akan melakukan gerakan- gerakan dan mencari puting ibu, memasukkan puting ke mulutnya secara benar dan menghisapnya dalam satu jam pertama kehidupan (Saleha,2009).

Inisiasi menyusu dini dapat memberi kehangatan bagi bayi, karena biasanya bayi baru lahir mengalami kedinginan atau hyphotermia, dan dengan dilakukannya proses insiasi menyusu dini, maka akan terjadi skin contact dimana kulit ibu bersifat termoregulator. Hal ini dapat dibuktikan pada penelitian yang dilakukan oleh Dr. Niels Bergman dari Afrika Selatan, yaitu jika bayi mengalami kedinginan, maka secara otomatis suhu kulit ibu akan naik dua derajat dan jika bayi kepanasan, suhu kulit ibu akan turun satu derajat (Roesli, 2008).

Walaupun pemerintah mendukung kebijakan WHO dan UNICEF yang merekomendasikan inisiasi menyusu dini sebagai tindakan life saving, tetapi dalam penerapannya IMD itu sendiri belum terlaksana dengan sempurna di beberapa rumah sakit, baik itu rumah bersalin umum, maupun di klinik praktek bidan, sehingga penerapannya masih perlu di kembangkan untuk dimaksimalkan pelaksanaan inisiasi menyusu dini. 
Berdasarkan hasil wawancara dan observasi yang dilakukan di RSIA Pertiwi Makassar, belum sepenuhnya dilakukan IMD. Hal ini dikarenakan kondisi yang ada di RSIA Pertiwi Makassar seperti proses persalinan, keadaan ibu dan sikap petugas kesehatan.

\section{B. Rumusan Masalah}

Berdasarkan latar belakang diatas, maka peneliti tertarik untuk meneliti bagaimana Pelakasanaan Inisiasi Menyusu Dini di RSIA Pertiwi Makassar.

\section{Tujuan Penelitian}

Tujuan penelitian ini adalah untuk mengetahui bagaimana Pelakasanaan Inisiasi Menyusu Dini di RSIA Pertiwi Makassar

\section{Manfaat Penelitian}

1. Manfaat Ilmiah

Diharapkan hasil penelitian ini dapat menjadi informasi dan bahan bacaan bagi peneliti berikutnya

2. Manfaat Praktis

Hasil penelitian ini diharapkan dapat menambah wawasan dan pengetahuan penulis pelaksanaan inisiasi menyusui dini.

3. Manfaat Penelitian

Bagi penulis sendiri merupakan pengalaman berharga dalam mengaplikasi ilmu yang diperoleh selama melakukan penelitian

\section{METODE PENELITIAN}

\section{A. Jenis Penelitian}

Jenis Penelitian pada hakekatnya merupakan suatu strategi untuk mencapai tujuan penelitian dan berperan sebagai pedoman atau penuntun peneliti pada seluruh proses penelitian (Nursalam, 2003). Jenis penelitian yang digunakan adalah penelitian dengan pendekatan deskriptif. Metode deskriptif dalam penelitian ini bertujuan untuk mengetahui Gambaran Pelaksanaan Inisiasi Menyusu Dini di RS Ibu dan Anak Pertiwi Makassar.

\section{B. Waktu dan Tempat Penelitian}

Penelitian ini dilaksanakan pada bulan Maret 2019 di Rumah Sakit Ibu dan Anak Pertiwi Makassar.

\section{Populasi dan Sampel}

a. Populasi

Populasi dalam penelitian ini adalah jumlah persalinan normal selama bulan Maret yaitu sebanyak 125 persalinan.

b. Sampel

Sampel merupakan bagian dari populasi (contoh), untuk dijadikan sebagai bahan penelaahan dengan harapan contoh yang dimbil dari populasi tersebut dapat mewakili (representative) terhadap populasinya

(Supangat, 2007).

Sesuai dengan tujuan penelitian maka teknik sampling yang digunakan yaitu teknik accidental sampling. Cara pengambilan sampel ini dilakukan dengan kebetulan bertemu. Sebagai contoh, dalam menentukan sampel apabila dijumpai ada, maka sampel tersebut diambil dan langsung dijadikan sebagai sampel utama (Hidayat, 2011). Dalam penelitian ini menggunakan teknik accidental sampling, maka besar sampel pada penelitian ini adalah 30 persalinan yang ada pada saat dilakukan penelitian.

\section{Instrumen Pengumpulan Data}

Instrumen yang digunakan dalam penelitian ini berupa observasi. Observasi merupakan suatu proses yang kompleks, suatu proses yang tersusun dari berbagai proses biologis dan psikologis dua diantaranya yang terpenting adalah proses-proses pengamatan (sugiono, 2012). Dimana peneliti melihat langsung Pelaksanaan Inisiasi Menyusu Dini di RSIA Pertiwi. Dalam observasi terdiri 6 prosedur/tindakan dalam penerapan inisiasi menyusu dini, dengan dua pilihan dilakukan dan tidak dilakukan. Tiga pernyataan yang harus ada dalam pelaksanaan IMD yaitu nomor 1,2 dan 4 . Dengan menggunakan skala Guttman jika dilakukan sesuai prosedur diberi nilai satu (skor=1) sedangkan tidak dilakukan sesuai dengan prosedur maka diberi nilai nol (skor=0).

\section{E. Prosedur Pengumpulan Data}

Dalam melakukan penelitian, prosedur pengumpulan data yang ditetapkan adalah sebagai berikut:

1. Memberikan penjelasan dan melakukan pendekatan kepada calon responden bahwa peneliti ingin berpartisipasi pada pertolongan persalinan.

2. Peneliti melakukan observasi pelaksanaan Inisiasi Menyusu Dini pada pertolongan persalinan dengan berpedoman pada lembar observasi. Setelah proses persalinan selesai peneliti memberi tanda cek $(\sqrt{ })$ pada lembar observasi di Ruang Nifas tanpa sepengetahuan responden dan sesuai dengan tindakan yang telah dilakukan oleh responden.

3. Apabila terdapat dua persalinan dengan waktu yang bersamaan di tempat yang berbeda, peneliti meminta bantuan inumerator yang sebelumnya telah diberi penjelasan tentang cara pengisian lembar observasi

\section{F. Pengolahan data dan Analisa Data}

1. Pengolahan data Tahap-tahap pengelolaan data adalah sebagai berkut : (Notoatmojo, 2005) 
a. Editing

Data yang telah dilakukan diperiksa segera mungkin berkenaan dengan ketepatan dan kelengkapan jawaban sehingga mempermudah pengolahan selanjutnya.

b. Coding

Memberikan kode jawaban secara angka atau kode tertentu sehingga lebih mudah ditabulasi. Dalam penelitian ini kode dicantumkan pada lembar observasi.

c. Skoring

Setelah lembar observasi dikumpulkan, kemudian pengolahan data dilakukan dengan pemberian skor dan penilaian, setiap tindakan yang dilakukan sesuai dengan langkah prosedur diberi skor 1 dan jika tidak sesuai diberi skor 0 . Hasil dari penjumlahan jawaban yang benar didapat skor total.

d. Penilaian

Setelah seluruh data terkumpul melalui lembar observasi, kemudian ditabulasi dan dikelompokkan sesuai dengan variabel yang diteliti.

e. Analisa data

Analisa data dilakukan secara univariat dengan melihat data yang terkumpul dan masing-masing jawaban responden ditampilkan dalam tabel distribusi frekuensi dan narasi.

\section{HASIL DAN PEMBAHASAN}

\section{A. Hasil Penelitian}

Penelitian ini dilakukan di Rumah Sakit Ibu dan Anak Pertiwi Makassar dengan jumlah persalinan sebanyak 30. Penelitian dilakukan dengan cara observasi yaitu mengamati langsung proses persalinan. Data yang diperoleh kemudian disajikan dalam bentuk tabel disertai narasi. Berikut ini peneliti akan menyajikan analisa univariat pada tiap variabel dalam bentuk tabel distribusi frekuensi.

1. Deskripsi Karakteristik Responden

Karakteristik responden pada penelitian ini mencakup usia ibu, status persalinan, dan pekerjaan.

a. Usia Ibu

Tabel I. Distribusi Frekuensi Responden Berdasarkan Usia Ibu bersalin Di RSIA Pertiwi Makassar

\begin{tabular}{ccc}
\hline Usia & Jumlah & Persentase \\
\hline $20<$ tahun & 2 & 6,6 \\
$20-35$ tahun & 25 & 83,3 \\
$>35$ tahun & 3 & 10 \\
\hline Total & 30 & 100 \\
\hline
\end{tabular}

Sumber : data primer
Berdasarkan tabel I didapat usia ibu bersalin yang berada di rentang usia $20<$ tahun sebanyak 2 orang $(6,6 \%)$, yang tertinggi berada di rentang usia 20-35 tahun $(83,3 \%)$ dan yang terendah adalah pada kelompok usia $>35$ tahun yaitu sebanyak 3 orang (10\%).

b. Status Persalinan

Tabel II. Distribusi Frekuensi Responden Berdasarkan Status Persalinan Di RSIA Pertiwi Makassar

\begin{tabular}{ccc}
\hline Status Persalinan & Jumlah & Persentase \\
\hline Primipara & 12 & 40 \\
Multipara & 10 & 33,3 \\
Gravida & 8 & 26,6 \\
\hline Total & 30 & 100 \\
\hline \multicolumn{4}{c}{ Sumber : data primer } \\
Berdasarkan tabel II & menunjukkan
\end{tabular}
bahwa distribusi responden berdasarkan status persalinan, yang tertinggi berada pada status persalinan primipara yaitu sebanyak 12 persalinan (40\%), kemudian diikuti multipara sebanyak 10 persalinan $(33,3 \%)$, dan yang terendah berada pada gravida yaitu sebanyak 3 persalinan $(26,6 \%)$.

c. Pendidikan

Tabel III. Distribusi Frekuensi Responden Berdasarkan Pendidikan Ibu Bersalin di RSIA Pertiwi Makassar

\begin{tabular}{ccc}
\hline Pendidikan & Jumlah & Persentase \\
\hline SD & 3 & 10 \\
SMP & 5 & 16,7 \\
SMA & 12 & 40 \\
PT & 10 & 33,3 \\
\hline Total & 30 & 100
\end{tabular}

Sumber:data Primer

Berdasarkan tabel III menunjukkan bahwa distribusi responden berdasarkan pendidikan ibu bersalin, yang tertinggi berada pada tingkat pendidikan SMA yaitu sebanyak 12 orang (40\%), kemudian diikuti PT sebanyak 10 orang $(33,3 \%)$, kemudian diikuti SMP sebanyak 5 orang $(16,7 \%)$, dan yang terendah SD terdiri 3 orang $(10 \%)$.

2. Pelaksanaan IMD di RSIA Pertiwi Makassar Tabel IV. Distribusi Frekuensi Berdasarkan Pelaksanaan IMD di RSIA Pertiwi Makassar

\begin{tabular}{ccc}
\hline $\begin{array}{c}\text { Pelaksanaan } \\
\text { IMD }\end{array}$ & Jumlah & Persentase \\
\hline Dilakukan & 3 & 10 \\
Tidak dilakukan & 37 & 90 \\
\hline Total & 30 & 100 \\
\hline \multicolumn{2}{c}{ Sumber : data primer }
\end{tabular}


Berdasarkan tabel IV menunjukkan bahwa pelaksanaan IMD di RSIA Pertiwi Makassar bahwa dari 30 persalinan hanya 3 persalinan (10\%) yang melakukan IMD sedangkan 27 persalinan $(90 \%)$ tidak melakukan IMD.

\section{B. Pembahasan}

Hasil penelitian dengan observasi yaitu mengamati langsung proses persalinan, dimana pengolahan data dengan uji frekuensi maka diperoleh data umum dan data khusus yang merupakan keadaan nyata yang diperoleh peneliti. Dalam pembahasan ini penulis mengacu pada teori dan data yang diperoleh yaitu sebagai berikut:

Berdasarkan hasil penelitian di RSIA Pertiwi Makassar menunjukkan bahwa dari sebanyak 30 persalinan, hanya 3 persalianan $(10 \%)$ yang melakukan IMD dengan benar dan 27 persalian (90\%) tidak melakukan IMD dengan benar.

Inisiasi Menyusu Dini adalah suatu rangkaian kegiatan dimana bayi segera setelah lahir yang sudah terpotong tali pusatnya secara naluri melakukan aktivitas-aktivitas yang diakhiri dengan menemukan puting susu ibu kemudian menyusu pada satu jam pertama kelahiran.

Menurut Hegar dkk, (2008) Inisiasi Menyusu Dini adalah meletakkan bayi di atas dada atau perut ibu segera setelah persalinan dan membiarkan bayi mencari puting susu ibu kemudian menghisapnya setidaknya satu jam setelah kelahiran. Masih ada sebagian persalinan yang belum mendapat pelaksanaan IMD pada waktu yang tepat setelah melahirkan, hal ini dikarenakan masih ada petugas kesehatan terutama penolong persalinan di RSIA Pertiwi Makassar tersebut yang belum banyak memahami hal-hal terkait ketepatan waktu pelaksanaan IMD. Padahal dampak Inisiasi Menyusu Dini bagi bayi adalah sebagai makanan dengan kualitas dan kuantitas yang optimal agar ASI segera keluar yang disesuaikan dengan kebutuhan bayi, memberikan kesehatan bayi dengan kekebalan pasif yang segera kepada bayi, meningkatkan kecerdasan, membantu bayi mengkoordinasikan hisap, telan dan nafas, meningkatkan jalinan kasih sayang ibu dan bayi, mencegah kehilangan panas (Ambarwati, 2008).

Dengan IMD pada 1 jam pertama dapan meningkatkan potensi keberhasilan menyusui secara eksklusif selama 6 bulan dan dilanjutkan dengan makanan pendamping ASI sampai bayi berumur 2 tahun. ASI saja sudah dapat mencukupi semua kebutuhan bayi. Inisiasi menyusu dini dalam satu jam setelah kelahiran merupakan yang penting untuk mengurangi kematian bayi dan mengurangi banyak kematian neonatal. Menyelamatkan 1 juta bayi dimulai dengan satu tindakan, satu pesan dan satu dukungan yaitu dimulai Inisiasi Menyusu Dini dalam satu jam pertama kelahiran.

IMD berperan dalam pencapaian tujuan Millineum Development Goals (MDGs) yang diantaranya Membantu mengurangi angka kematian anak balita. Saat ini sekitar $40 \%$ kematian balita terjadi pada satu bulan pertama kehidupan bayi. Inisiasi menyusu dini akan mengurangi $22 \%$ kematian bayi di bawah usia 28 hari. Pemberian ASI eksklusif akan mengurangi 13\% kematian bayi dan memberikan makanan pendamping ASI (makanan keluarga) akan menurunkan 6\% kematian anak balita. Dengan demikian kematian balita dapat dicegah dengan IMD, pemberian ASI eksklusif dan makanan pendamping ASI sebesar $41 \%$. ASI dan menyusui secara eksklusif akan menciptakan faktor lingkungan yang optimal untuk meningkatkan kecerdasan bayi melalui pemenuhan semua kebutuhan awal dari faktor-faktor lingkungan. Dari uraian di atas dapat ditarik kesimpulan bahwa bayi yang diberi ASI adalah bayi yang lebih sehat, IQ lebih tinggi, EQ lebih baik dan SQ lebih baik.

Dalam penelitian ini menunjukkan bahwa petugas kesehatan kurang mengetahui tentang tatalaksana IMD dan kapan IMD sebaiknya langsung diberikan. Karena dalam kenyataannya setelah bayi lahir, petugas kesehatan membersihkan dan membedong bayi baru lahir setelah itu baru diberikan kepada ibunya atau diletakkan disampingnya, setelah itu ibu lalu dianjurkan untuk memberi ASI kepada bayinya. Hal ini juga dikarenakan oleh beberapa faktor yaitu bayi dikhawatirkan merasa kedinginan kemudian langsung dibawa keruang bayi, ibu kelelahan dan harus dijahit setelah proses pada episiotomi persalinan, kebiasaan petugas kesehatan, ASI ibu yang kurang cukup dan kebiasaan atau tatanan budaya yang berlaku dimasyarakat maupun prosedur yang ada di rumah Sakit. Adapun alasan lain yang membuat tenaga kesehatan tidak malakukan IMD adalah kondisi ibu yang masih lemah, sehingga tenaga kesehatan lebih memprioritaskan perawatan ibu untuk memperbaiki kondisi ibu. Kurangnya dukungan pada ibu yang sedang bersalin, membuat ibu cenderung lebih memilih beristirahat setelah proses persalinan daripada harus kesulitan membantu mengawasi bayi untuk melakukan IMD.

Menurut UNICEF (2006) dalam Berutu (2010), banyak sekali masalah yang dapat menghambat pelaksanan IMD antara lain:

1. Kurangnya kepedulian terhadap pentingnya IMD;

2. Kurangnya konseling oleh tenaga kesehatan dan kurangnya praktek IMD;

3. Adanya pendapat bahwa suntikan vitamin $\mathrm{K}$ dan tetes mata untuk mencegah penyakit gonorhea harus segera diberikan setelah lahir, padahal sebenarnya tindakan ini dapat ditunda setidaknya salama satu jam sampai bayi menyusu sendiri.

4. Masih kuatnya kepercayaan keluarga bahwa ibu memerlukan istirahat yang cukup setelah melahirkan dan menyusui sulit dilakukan; 
5. Kepercayaan masyarakat yang menyatakan bahwa kolostrum yang keluar ada hari pertama tidak baik untuk bayi;

6. Kepercayaan masyarakat yang tidak mengizinkan ibu untuk menyusu dini sebelum payudara di bersihkan.

Pelaksanaan IMD tentunya membutuhkan kerjasama antara petugas kesehatan yang menolong persalinan dengan ibu dan keluarganya. Setiap tindakan medis tetap harus membutuhkan persetujuan dari keluarga, sebelum IMD dilakukan tetap harus dikonsultasikan kepada keluarga tentang manfaat dan pentingnya ASI. Sosialisasi oleh dokter,perwat dan bidan tentu dapat dilakukan sebelum ibu melahirkan. Misalnya, pada tiap kali kunjungan ANC terutama trimester ke 3, penggunaan media cetak dan visual juga akan membantu sosialisasi IMD di masyarakat.

\section{PENUTUP}

\section{A. Kesimpulan}

Penelitian ini dilakukan di Rumah Sakit Ibu dan Anak Pertiwi Makassar dengan sampel sebesar 30 persalinan. Dari hasil penelitian diperoleh, sebanyak 27 persalinan (90\%) yang tidak melakukan IMD dengan tepat dan 3 persalinan $(10 \%)$ yang melakukan IMD dengan tepat

\section{B. Saran}

1. Bagi RSIA Pertiwi Makassar

Rumah Sakit perlu membuat protap untuk petugas kesehatan agar di setiap persalinan dilakukan IMD segera setelah bayi lahir.

2. Bagi Keluarga

Perlunya dukungan suami dan keluarga dalam mendampingi proses persalinan dalam melakukan IMD.

3. Bagi Peneliti

Diharapkan kepada peneliti selanjutnya untuk melakukan penelitian lebih lanjut tentang faktor-faktor dan variabel lain yang berhubungan dengan IMD untuk meningkatkan hasil penelitian.

\section{DAFTAR PUSTAKA}

Ambarwati, Retna E. 2009. Asuhan Kebidanan Masa Nifas; Mitra Cendikia Pres ;Jogjakarta.

Baskoro, Anton. 2008. ASI: Panduan Praktis Ibu Menyusui: Banyu Medika; Yogyakrta.

Depkes RI. 2008. Standarisasi Program Kesehatan $\underline{\text { Ibu, Bayi, Anak, Balita di Indonesia }}$

Hidayat, Aziz Alimul. 2011. Metode Penelitian Keperawatan dan Analisa Data. : Salemba Medika; Jakarta.
JNPK-KR. 2008. Pelatihan Klinik Asuhan Persalinan Normal, Buku Acuan. Ed.4 revisi. Jakarta: Jaringan Nasional Pelatihan KlinikKesehatan Reroduksi.

Kristiyansari, W., 2009. ASI:Menyusui dan Sadari: Nuha Medika ;Yogyakarta.

Notoadmodjo Soekidjo. 2005. Metodologi Penelitian Kesehatan. Jakarta : Rineka Cipta

Nursalam. 2003. Konsep dan Penerapan Metodologi Penelitian Ilmu Ilmiah Keperawatan: Penerbit Salemba Medica; Jakarta

Roesli, U, 2001. Mengenal ASI Eksklusif Seri I, Trubus Agriwidya, Jakarta.

Siregar,A. 2004. Pemberian ASI Eksklusif dan Faktor-faktor yang mempengaruhinya, Fakultas Kesehatan masyarakat Universitas: Sumatra Utara

Sitti, saleha. 2009. Asuhan Kebidanan pada Masa Nifas: Salemba Medika; Jakarta

Soetjiningsih, 2002, ASI : Petunjuk untuk Tenaga Kesehatan, Edisi 1, EGC, Jakarta

Supangat, Andi. 2007. Statistika. Jakarta: Kencana Prenada Media Group

Suryaprajoyo, Nadine. 2009. Konsep Penerapan ASI Eksklusif. Bandung: EGC

Wiknjosastro, Hanifa, 2007. Ilmu Kebidanan Yayasan Bina Pustaka Sarwono Prawirohardjo. Jakarta 